\title{
Mapeando os estudos sobre gênero textual: trilhas de pesquisa e ensino
}

\author{
Mapping studies on Genre: research and teaching tracks \\ Maria do Socorro OLIVEIRA* \\ Universidade Federal do Rio Grande do Norte (UFRN)
}

\begin{abstract}
RESUMO: A partir de um mapeamento dos estudos sobre gênero textual, este estudo objetiva oferecer um corpo de conceitos básicos que serve de ligação entre a pesquisa teórica e a prática do professor em sala de aula, com vistas a se promover na escola um trabalho pedagógico consciente e produtivo. Entendemos que uma melhor compreensão dessa unidade de estudo por professores (e não apenas por pesquisadores) implica um redirecionamento tanto da postura do professor quanto de sua prática em sala de aula. Afinal, o que o professor ensina e como ele ensina decorrem da compreensão que ele tem dos fenômenos de linguagem. Diferentes concepções originam diferentes práticas.
\end{abstract}

PALAVRAS-CHAVE: Gênero Textual. Pesquisa. Ensino.

ABSTRACT: Based on a mapping of studies on genre, this study aims to provide a body of basic concepts that serves as a link between theoretical research and teacher practice in the classroom, in order to promote a conscious pedagogical work in the school and productive. We understand that a better understanding of this unit of study by teachers (and not only by researchers) implies a redirection of both the teacher's posture and his classroom practice. After all, what the teacher teaches and how he teaches stems from his understanding of language phenomena. Different conceptions give rise to different practices.

KEYWORDS: Genre. Search. Teaching.

* É Professora Titular de Linguística e Linguística Aplicada do Departamento de Letras da UFRN. Vinculada ao Programa de Pós-Graduação em Estudos da Linguagem (PPgEL) e ao PROFLETRAS. Email: msroliveira.ufrn@gmail.com 


\section{Introdução}

Em decorrência das postulações dos PCN (1998), a noção de gênero textual ganhou espaço, marcando entrada no discurso dos professores que começaram a utilizála no contexto escolar sem que, de fato, tivesse havido por parte deles uma efetiva apropriação do conceito. Assinale-se que, ao ser promulgado pelos PCN o ensino de gêneros na escola, as discussões desenvolvidas sobre esse conceito em âmbito nacional, tanto em nível teórico quanto aplicado, ainda estavam em fase incipiente ${ }^{2}$. À época, a unidade de ensino recomendada, usualmente, era o texto. Esse fato explica o desconforto dos professores, em geral, para atender a essa recomendação oficial.

Passadas duas décadas da disseminação dessa orientação, muitos dos professores que afirmam estar trabalhando com gênero textual, ainda costumam explorar apenas o aspecto composicional do gênero (a dimensão textual ou linguística) ou a variedade de tipos de textos, conforme a orientação já consagrada, tradicionalmente, na escola. Não se pode deixar de reconhecer que muito esforço foi empreendido com vistas à elucidação de questões ligadas à didatização dos gêneros textuais, seja por meio de políticas públicas no campo do letramento (Pró-Letramento, Olimpíada de Língua Portuguesa, Programa Nacional do Livro Didático) seja por meio de iniciativas isoladas, privadas ou públicas. Mesmo com esse investimento linguístico/educacional, professores ainda se perguntam: qual a diferença entre trabalhar com texto e trabalhar com gênero? Essa indagação revela que, de modo geral, o professor ainda não se sente confortável ou, suficientemente, seguro no processo de didatização do gênero. Temos a clareza de que muitas variáveis podem interferir nesse processo, por exemplo, conhecimentos linguísticos, dispositivos didáticos, estratégias operacionais. Todavia, nos arriscamos, nesta reflexão, a problematizar a situação, examinando: 1) em que medida os estudos linguísticos são importantes para fundamentar o processo de didatização dos gêneros textuais; e 2) se o professor detém conhecimento linguístico a esse respeito. Dito de outro modo, se a prática do professor é informada teoricamente.

\footnotetext{
${ }^{2}$ Não se quer dizer com isso que o gênero textual não fosse objeto de estudo de pesquisadores brasileiros. Já nessa época, destacavam-se os trabalhos de Marcuschi (UFPE) e de outros pesquisadores em outros centros de pesquisa do país (PUC/SP; UFSC/PR). Destaque-se, entretanto, que a questão só foi discutida, de forma mais ampla e institucionalizada, no I Simpósio Internacional de Estudos de Gêneros Textuais (I SIGET), em 2003, na Universidade Estadual de Londrina (PR).
} 
Parece-nos que muito do que o professor faz no que concerne a esse tópico é operado de modo bastante intuitivo, sem uma clara fundamentação teórica. Em razão disso, assumimos, neste trabalho, que essa é uma questão merecedora de reflexão. Afinal, quando se ensina gênero, é preciso ter em mente: Gênero, segundo que tipo de abordagem teórica? A partir de que orientação de ensino-aprendizagem? (OLIVEIRA, 2010).

Orientado por essas questões, este estudo objetiva resgatar os movimentos epistemológicos presentes nos estudos sobre gênero textual tanto do ponto de vista teórico quanto do aplicado. Trata-se de uma pesquisa de natureza exploratória, dirigida a professores em formação inicial e em serviço, a qual busca configurar-se como um guia introdutório para a compreensão do conceito de gênero textual. O propósito aqui não é trazer contribuições teóricas para os estudos de gênero nem, tampouco, apresentar experiências didáticas destinadas à aplicação em sala de aula, mas oferecer um corpo de conceitos básicos que sirva de ligação entre a pesquisa teórica e a prática do professor em sala de aula, de modo a contribuir para a compreensão desse fenômeno textual/discursivo e, consequentemente, das implicações da tarefa de ensinar/aprender as práticas de linguagem no contexto escolar.

Entendemos que uma melhor compreensão dessa unidade de estudo por professores (e não apenas por pesquisadores) implica um redirecionamento tanto da postura do professor quanto de sua prática em sala de aula. Não há dúvida de que aquilo que o professor ensina e como ele ensina decorrem da compreensão que ele tem do fenômeno de linguagem em estudo. Iniciemos, então, a tarefa!

\section{Mapeando os estudos sobre gênero textual: diferentes perspectivas teóricas}

A preocupação com 'gênero' é, de fato, antiga. Remonta aos estudos da poética, com Platão, e da retórica, com Aristóteles, caracterizados, sobretudo, por contribuições de natureza tipológica. Nesses estudos, o foco de atenção era sempre a classificação de: 1) formas literárias distintas: poesia/prosa; lírico/épico/dramático; tragédia/comédia; 2) estilos clássicos: elevado, médio e humilde; e 3) tipos de discurso: deliberativo, judiciário, demonstrativo ou epidítico (distinguidos pela retórica). 
O reconhecimento, porém, da incompletude e das dificuldades que esses modelos tipológicos apresentam e da importância de se estabelecer critérios de descrição e explicação que deem conta da dinâmica da interação e das matrizes pragmáticas que constituem a variedade textual, tem redirecionado os estudos de gênero, favorecendo o surgimento de várias abordagens centradas na importância das 'redes de práticas textuais' e dos diversos 'contextos' que se entrelaçam na constituição desse construto.

Tradicionalmente, os estudos de gênero centravam-se nas regularidades textuais, especialmente nas convenções de forma e de conteúdo dos textos literários. Contemporaneamente, essa categoria vem sendo reconceitualizada. Os estudos sobre o assunto têm-se voltado para as regularidades das esferas da atividade humana, tentando, todavia, conciliar os aspectos de natureza textual com o entendimento social e cultural da linguagem em uso, concentrado em textos do cotidiano e não apenas nas formas literárias.

Essa abertura, proveniente do interesse por variados textos, situados em domínios de atividades diferentes, e pela adoção de outras lentes interpretativas, tem ocasionado o surgimento de um novo quadro ontológico constituído por epistemologias diversas - cognitivistas, enunciativas, interacionistas, sócio discursivas, pragmáticotextuais, semióticas, sócio retóricas etc., as quais reclamam trabalhos de sistematização no campo, tais como: a identificação de atalhos, de trilhas conceituais seguidas pelos estudiosos da área ${ }^{3}$.

Os trabalhos de Flowerdew (2002) e Hyon (1996) constituem-se em tentativas de mapeamento do campo. Flowerdew (2002, p. 91) dicotomiza teóricos em campos linguísticos e não linguísticos, enfatizando que a abordagem ESP (English for Specific Purpose) e a escola australiana, as quais aplicam a teoria funcional, concentram-se em aspectos léxico-gramaticais e na realização retórica dos propósitos encaixados no gênero, enquanto o grupo da nova retórica é mais focalizado no contexto situacional propósitos e funções do gênero bem como atitudes, crenças, valores e comportamentos dos membros da comunidade discursiva nos quais os gêneros estão situados.

Hyon (1996) situa as teorias de gênero em três campos: 1) o da escola de Sydney, baseado no trabalho da linguística sistêmico-funcional de Halliday (1985); 2) o

${ }^{3}$ MEURER; BONINI; MOTA-ROTH (2005), ao mapearem o campo dos estudos de gêneros, propõem três abordagens: sócio-semióticas, sócio-retóricas e sócio-discursivas. Trilhas conceituais acerca da noção de 'gênero' são também identificadas nos estudos de BUNZEN (2004) e de FAKHRUDDIN; HASSAN (2015). 
campo dos estudos de $\mathrm{ESP}^{4}$, cujo expoente mais famoso é Swales (1990) com o trabalho sobre 'moves' em introduções de artigo científico; e 3) o campo da nova retórica para o qual a noção de gênero tem sido vista basicamente como social, estando vinculada ao contexto do escritor e da audiência bem como à comunidade a que pertence. Fazem parte da última corrente as contribuições de pesquisadores norte-americanos e canadenses como Charles Bazerman, Carolyn Miller, Aviva Freedman, Anne Freedman, Richard Coe, Peter Medway, entre outros (FREEDMAN; MEDWAY, 1994) 5 .

Embora os estudos de Swales (1990) estejam localizados no campo dos estudos de ESP, em razão de esse linguista aplicado mostrar-se interessado especificamente no ensino do inglês instrumental, alguns autores inserem os trabalhos desse pesquisador na concepção sócio-retórica (ARAÚJO, 1996; SILVEIRA, 2005; MEURER; BONINI; MOTTA-ROTH, 2005). Johns (2002) problematiza a vinculação de Swales unicamente aos estudos de ESP, usando como justificativa a natureza eclética das influências teóricas que marcou o trabalho dele além do fato de os estudos em ESP estarem vinculados a diferentes correntes teóricas. Para fins de delimitação, preferimos aqui situar os seus trabalhos na concepção sócio-retórica, considerando os argumentos e as posições dos pesquisadores aludidos e as nossas intenções neste trabalho.

Além das tradições sistêmico-funcional e sócio-retórica, é importante destacar:

1. o trabalho da escola de Genebra, representada pelo grupo de pesquisadores Jean-Paul Bronckart, Bernard Scheneuwly, Joaquim Dolz, entre outros, cuja abordagem enfatiza os aspectos sócio-históricos da produção textual;

2. os estudos de Bakhtin (1992), vistos neste trabalho como fonte geradora, inspiradora dessas abordagens - um trabalho verdadeiramente fundador;

3. a análise etnográfica, postulada como de natureza situada já que tem como base o cruzamento do texto com fronteiras de contexto (DEVITT; REIFF; BAWARSHI, 2004).

Os estudos incluídos nos itens 1 e 2, elencados anteriormente, serão mencionados aqui, como fazendo parte da abordagem sócio-discursiva (ver adiante).

\footnotetext{
${ }^{4}$ Nessa tendência, se inserem os trabalhos de Bathia (1993) sobre o uso da linguagem em ambientes profissionais.

${ }^{5}$ Há quem fale em uma abordagem brasileira que tenta reunir, na forma de síntese, contribuições de várias escolas (ver abordagem mestiça, referida por Motta-Roth (2008)). Com base no caráter difuso das descrições desse fenômeno, julgamos que é difícil falar de uma abordagem brasileira, entendida como um movimento uniforme (ver VIAN JR(2012) e Bezerra (2016)).
} 


\subsection{Abordagem sistêmico-funcional}

Na abordagem sistêmico-funcional, a reflexão sobre gênero tem recebido a atenção especial de Hasan (1985) e Martin (2000) cujo ponto central reside no interesse em analisar a linguagem como um sistema sócio-semiótico. Esses estudos baseiam-se, fundamentalmente, nos trabalhos de Halliday (1985) para quem a linguagem se refere a uma rede de escolhas (é, por isso, de natureza sistêmica), estando associada à atividade social em um dado contexto (é, por isso, de natureza funcional). Nesta teoria, a unidade de análise é o texto, entendida como a "instância de uso da linguagem viva que está desempenhando um papel num contexto de situação" (HALLIDAY, 1989, p. 10). O texto reflete as escolhas gramaticais, lexicais e semânticas inerentes ao contexto situacional (registro) e ao contexto cultural em que é produzido (gênero). Nesse sentido, registro (campo, as relações e o modo) e gênero (estrutura) estão intimamente relacionados, sendo vistos como sistemas abstratos materializados pela língua. Para definir a estrutura potencial de um gênero (EPG) e a sua configuração contextual (CC), Hasan (1989) toma como ponto de partida o registro. Martin (2000), ao contrário, afirma que é o gênero (contexto de cultura) que pré-seleciona as variáveis de registro. Para ele, a cultura é vista como um sistema de gêneros. Em outras palavras, a noção de gênero diz respeito às atividades linguísticas inerentes a uma determinada cultura.

\subsection{Abordagem sócio-retórica}

Filiados a esta abordagem, encontram-se os estudos de Swales (1990), Miller (1994) e Bazerman (2005) cujas postulações destacam o caráter sócio-cultural dos gêneros, entendidos como 'formas de ação conjunta' que nos permitem exercer papéis, realizar propósitos e, de modo significativo, participar em situações típicas de comunicação.

As contribuições de Swales (1990) demonstram o seu interesse na teoria, análise e ensino dos gêneros textuais, estando a sua obra voltada, especialmente, para a análise de gêneros textuais em contextos acadêmicos e profissionais. $\mathrm{O}$ seu trabalho de pesquisa trata de três conceitos-chave: comunidade discursiva, gênero e propósito comunicativo.

O conceito de 'comunidade discursiva' é definido por Swales (1990, p. 9) como "redes sócio-retóricas que se formam a fim de atuar em conjuntos de objetivos comuns", devendo ser caracterizadas pelas convenções discursivas e pelos objetivos 
compartilhados. Para ele, o 'gênero' compreende uma classe de eventos comunicativos, cuja condição fundamental é o 'propósito comunicativo' compartilhado pelos membros de uma comunidade discursiva.

Seu trabalho deu origem ao modelo CARS (Create a Research Space) desenvolvido com base em um corpus de 48 introduções de artigos de pesquisa as quais apontaram regularidades - movimentos e passos (moves e steps) - unidades e subunidades retóricas (SWALES, 1990, p. 140). Este modelo tem-se mostrado altamente produtivo para a análise de exemplares de gêneros, particularmente no domínio científico. É o que atestam inúmeras pesquisas brasileiras (ARAÚJO, 1996; BIASI-RODRIGUES， 1998 (BIASI-RORIGUES， SILVEIRA， 2005; MEURER; BONINI; MOTTA-ROTH, 2005).

Baseada em duas noções-chaves - recorrência e ação retórica -, Miller (1994) considera o gênero uma "ação social". Funcionando como uma convenção estabelecida em uma dada cultura, os gêneros são segundo Miller (1994, p. 24) "ações retóricas tipificadas" realizadas em situações recorrentes. Sua análise fundamenta-se em critérios eminentemente pragmáticos, uma vez que salienta a importância da "situação retórica" percebida como um componente integrador no qual atuam, conjuntamente, o contexto, a motivação dos participantes e os efeitos por eles pretendidos.

Para Bazerman (2005, p. 31), os gêneros emergem nos processos sociais. São fenômenos de reconhecimento psicossocial que fazem parte de um sistema de atividades socialmente organizado, ou seja, "são parte do modo como os seres humanos dão forma às atividades sociais". É um agir de modo típico dentro de um sistema de atividades (participantes, papéis, atividades, organizações/campo disciplinar/comunidade). Sua abordagem coloca o gênero como um meio de agência através da qual as pessoas tornam as suas intenções compreensíveis para os outros (BAZERMAN, 2006).

\subsection{Abordagem sócio-discursiva}

Para fugir da confusão terminológica que envolve as discussões sobre gênero, Bronckart (1999, p. 72) deixa, a propósito, a noção vaga e provisória. Ele tece sua argumentação em torno do texto, entendido como "toda unidade de produção de linguagem situada, acabada e auto-suficiente" (BRONCKART, 1999, p. 75). Acrescenta que "Na medida em que todo texto se inscreve, necessariamente, em um conjunto de textos ou em um gênero, adotamos a expressão gênero de texto em vez de gênero de 
discurso". Para ele, os textos são produtos da atividade humana e, como tais, estão articulados às necessidades, aos interesses e às condições de funcionamento das formações sociais no seio das quais são produzidas. A expressão 'gênero de texto' corresponde, assim, a 'espécies de textos' ou 'modos de fazer textos', em outros termos, um instrumento para agir discursivamente. Esta abordagem é conhecida como interacionista sócio-discursiva (ISD).

Ao tratar das esferas de utilização da língua, Bahktin ([1979] 1992, p. 179), afirma "cada esfera de utilização da língua elabora seus tipos relativamente estáveis de enunciados (orais e escritos)", sendo estes chamados de gêneros do discurso. Esses enunciados manifestam-se de forma específica em cada esfera de comunicação, sendo constituídos por três elementos: o conteúdo temático (um assunto ou tópico), o estilo verbal, correspondente à seleção dos recursos lexicais, fraseológicos e gramaticais da língua, e a construção composicional (esquemática). Apesar de chamar a atenção para a riqueza e heterogeneidade dos gêneros, motivadas pela crescente complexidade das atividades humanas e da sociedade moderna que amplia, faz surgir e desaparecer certos gêneros, Bahktin diferencia os gêneros primários (simples ou do cotidiano) dos gêneros secundários (complexos - permitidos pela sofisticação sociocultural e pelo grafocentrismo/letramento). Essa divisão, vale lembrar, não deve ser interpretada como um recurso classificatório fixo, mas como algo em constante inter-relação e dependente das transformações históricas.

\subsection{Abordagem etnográfica}

A abordagem etnográfica, segundo Devitt, Reiff e Bawarshi (2004), fornece uma análise situada do gênero que cruza texto e fronteiras de contexto. Capacita escritores a interpretarem ações comunicativas particulares, provendo, desse modo, acesso a comunidades ou a culturas não familiares e, também, a formas de uso da linguagem consideradas poderosas na comunidade. Bawarshi e Reiff (2013, p. 254) chamam a atenção para o fato de que, em razão da natureza holística do método etnográfico,

pedagogias de gênero baseadas na etnografia evidenciam "como padrões de comportamento linguístico e retórico se relacionam com padrões de comportamento social", de forma complementar. $\mathrm{Na}$ verdade, esse trabalho traduz-se como uma intersecção com os estudos da nova retórica.

\subsection{Reflexões sobre o mapeamento teórico}


O que se observa no mapeamento dessas teorias é a dificuldade de se criar um quadro ontológico capaz de delimitar o construto - há tanto um campo unificador quanto dispersor. Embora a noção de gênero seja descrita de forma muito próxima em algumas abordagens, a terminologia adotada é extremamente flutuante (MEURER; BONINI; MOTA-ROTH, 2005), registrando-se também o cruzamento de construtos teóricos diferentes que dificulta, enormemente, a compreensão do fenômeno (OLIVEIRA, 2000), principalmente por parte do professor que, geralmente, procura se guiar por esses argumentos de autoridade construídos no campo científico.

No que diz respeito a esse aspecto unificador, há entre os pesquisadores o consenso de que gêneros são complexos. Se escolhermos analisá-los, de forma apartada, em termos de aspectos textuais versus ações sociais, comunidades de prática, estruturas de poder ou redes e modalidades nas quais eles operam, estaremos tendo apenas uma visão parcial do que se dá.

Essa complexidade leva muitos pesquisadores a olhar o gênero como uma entidade multidimensional que inclui o textual, o social e o político, observando-se também que o conhecimento 'genérico' perpassa vários domínios: o formal, o retórico, o processual e o temático os quais interagem e se sobrepõem, especialmente por parte dos escreventes mais experientes. A partir desse olhar, o gênero resultaria de uma relação funcional entre forma e situação (JOHNS, et al., 2006, p. 245) ou entre tipo de texto e situação retórica (COE, 2002, p. 197). Contribuições, nesse sentido, são animadoras.

\section{Mapeando posturas didáticas sobre gênero textual}

A dispersão que se observa no campo teórico faz-se presente também no campo aplicado, especialmente no que diz respeito a se ensinar os gêneros de modo explícito (pedagogia explícita) ou implícito (pedagogia de imersão) e/ou no que se refere à função dos gêneros nas diferentes orientações de letramento (OLIVEIRA, 2010). No domínio da didatização dos gêneros, observam-se, de modo geral, duas tradições: uma voltada para o ensino explícito - abordagens sistêmico-funcional (ASF) e sóciodiscursiva (aqui incluída a abordagem referida como ISD) - e outra voltada para o ensino implícito - abordagem sócio-retórica.

\subsection{Abordagens de gênero por meio de um ensino explícito (pedagogia explícita)}


$\mathrm{Na}$ abordagem sistêmico-funcional, uma das preocupações é com a construção de um currículo escolar explícito com base em gêneros (gêneros curriculares, em uma visão holística e transdisciplinar). O argumento principal é que para os alunos adquirirem conhecimentos e terem acesso à aprendizagem, eles precisam controlar os gêneros escritos mais valorizados na esfera comunicativa/disciplinar (relatos, argumentações, explicações, procedimentos etc.). Esse controle resultaria de um ensino explícito dos gêneros que se constituiriam em instrumentos de mudança e empoderamento social (CHRISTIE, 1999; ROTHERY, 1996). Outra função dessa proposta seria preparar os alunos para participarem, na escola, das práticas de letramento presentes na comunidade, por exemplo, a produção de uma carta solicitando emprego. Segundo Macken-Horarik (2002, p. 26, apud BAWARSHI; REIFF, 2013), uma pedagogia explícita de gêneros deve ser desenvolvida em um 'ciclo de ensinoaprendizagem' que “envolve três estágios: modelagem, negociação conjunta do texto e construção independente do texto". Trata-se de uma pedagogia visível, centrada no professor e nos objetos de ensino, observando-se a progressão dos textos e um currículo em espiral.

$\mathrm{Na}$ abordagem sócio-discursiva de origem franco-suíça (ISD) e na bakhtiniana, os gêneros são pensados como uma forma de articulação entre as práticas sociais e os objetos de ensino. Na ISD, são explorados como mega-instrumentos que fundam a possibilidade de comunicação (participação nas atividades sociais) e de aprendizagem (desenvolvimento das funções superiores). O objetivo não é considerar os gêneros objetos reais de ensino-aprendizagem, mas usá-los como quadros da atividade social em que as ações de linguagem se realizam (BRONCKART, 1999). Na verdade, o objeto de ensino são as operações de linguagem necessárias para essas ações - os tipos de discurso que entram na composição dos textos e os mecanismos lingüísticos que garantem a coesão e coerência dos textos -, as quais, dominadas, constituem as capacidades de linguagem (MACHADO, 2005, p. 258). É em função disso, que o grupo adotou um sistema de 'agrupamentos de gêneros' - narrar, relatar, argumentar, transmitir conhecimento e regular comportamentos - a ser explorado em 'sequências didáticas', entendidas como a unidade de trabalho escolar. As sequências didáticas e os agrupamentos de gêneros permitiriam a questão da progressão de gêneros. Na ISD, conforme se percebe, o foco de atenção é o texto.

$\mathrm{Na}$ abordagem de ensino à luz dos princípios bakhtinianos, espera-se que a prática dos gêneros discursivos se assente na realidade dos aprendizes vistos como 
atores históricos e sociais em constante construção da subjetividade. Com foco nos aspectos ideológicos da linguagem, esta perspectiva de trabalho enfatiza a natureza dialógica e valorativa dos processos de enunciação na vida real.

\subsection{Abordagens de gênero por meio de um ensino implícito (pedagogia da imersão) ${ }^{6}$}

Por entender os gêneros como dinâmicos, sujeitos à mudança e até ao desaparecimento, esta abordagem problematiza o ensino prescritivo (pedagogia explícita) dos gêneros. Seus seguidores (JOHNS, 2006; KERN, 2000; FREEDMAN, 1987 apud BAWARSHI; REIFF, 2013) argumentam que o processamento textual deve estar intrinsecamente vinculado ao seu contexto retórico, o que significa olhar o gênero sempre a partir de questões como: onde, porque é usado, quem usa, sob que condições e quando, atendendo não só às necessidades comunicativas dos sujeitos escritores mas também ao interesse em dar voz ao indivíduo - ação lingüística que teria de estar vinculada a um projeto mais amplo de natureza pedagógica e política.

Para esta tradição, a 'naturalização dos gêneros' (JOHNS, 1995) ou o processo de 'simulação dos gêneros' constitui-se no ponto nevrálgico do ensino explícito de gêneros. Nesse processo de didatização, criticado por vários estudiosos, os gêneros são removidos dos contextos sócio-culturais dinâmicos e complexos que lhes dão origem, sendo localizados fora de situações de vida própria de seu uso (BAZERMAN, 2005). Conforme chama a atenção Johns (1995), na medida em que os gêneros migram do seu contexto original para o contexto da escola, eles se tornam um texto para estudo e não um veículo de informação.

Fundamentada no respeito ao conhecimento situado e no papel do contexto na linguagem, a tradição retórica julga que é difícil (ou impossível) montar um modelo ou currículo com base em gêneros. Antes, defende a pedagogia da imersão, argumentando que a apropriação de gêneros ajuda os alunos a descobrirem o que pode ou não ser dito ou feito através deles em determinados contextos disciplinares. Esse recurso de mediação, possibilitado pelos gêneros, sinaliza o quanto é importante preparar os alunos para navegarem retoricamente em contextos disciplinares diversos (BAWARSHI, 2003) - tarefa que exige, naturalmente, conexão aos sistemas de valor próprios de cada

6 O termo 'pedagogia da imersão' está aqui relacionado ao ensino implícito de gêneros. Nessa abordagem, a aprendizagem de um gênero dá-se "no decorrer da escrita - no próprio desempenho" e no "aprender a escrever, escrevendo". Trata-se de uma pedagogia que enfatiza os processos composicionais, a invenção e o feedback externo. É a partir desse feedback que "os aprendizes confirmam ou modificam seu mapa do gênero", conforme afirma FREEDMAN (1987, p. 102, apud BAWARSHI; REIFF, 2013). 
audiência disciplinar. Se as escolhas retóricas indexam membros em grupos sociais, conforme afirma Hyland (2005), os aspectos interpessoais são essenciais no uso dos gêneros.

Aos aprendizes com dificuldade para relacionar textos a seus contextos significativos, a análise de gênero pode também ajudar na interação entre culturas e textos, entre o que Swales (1998) chama de 'modos de vida' e 'modos de textos'. Esse processo de 'intertextualidade' e 'intercontextualidade', parece-nos, só se efetiva por meio da pedagogia da imersão que favorece o cruzamento entre as vozes locais, os discursos sem poder, e as vozes institucionais, ligadas aos discursos de poder da cultura letrada em uma sociedade tecnológica, bem como a construção de uma visão complexa de gênero que introduz, gradualmente, os alunos nas diversas dimensões do gênero linguística, formal, temática, retórica, cultural, procedimental - e no modo como essas dimensões interagem, além de ajudar a apagar as relações de poder que os gêneros constroem e reforçam (HYLAND, 2003).

Figura 1 - Um modelo de análise do gênero (JOHNS et al ., 2006, p. 239) 


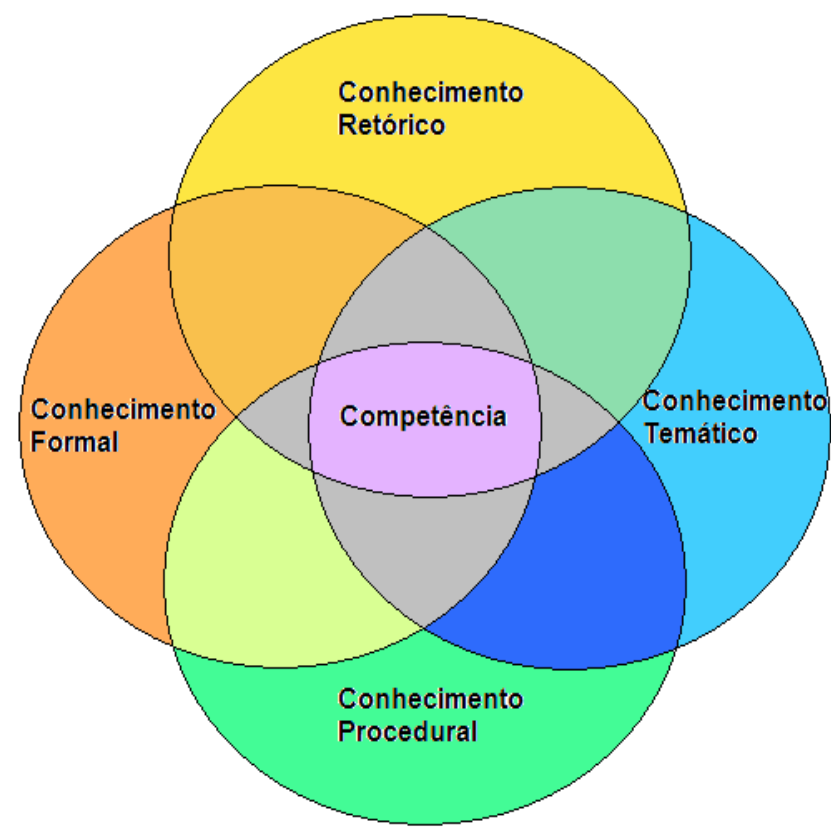

Com vistas a esse processo de apropriação dos gêneros, Devitt, Reiff e (2004, p. 44-94) sugerem uma abordagem alternativa para o ensino de gêneros - a etnográfica que inclui uma série de atribuições ou tarefas.

Uma primeira tarefa é ter os alunos como pesquisadores de um campo (uma aula, uma organização profissional ou acadêmica, um lugar de trabalho etc.). Isso exige: 1. selecionar e ganhar acesso ao lugar; 2. observar e descrever as atividades, participantes, tipos de interação, assuntos discutidos e ambientes; 3. examinar os padrões de uso da linguagem.

Uma segunda é pedir aos alunos para examinarem os padrões de linguagem encaixados no grupo ou cultura (o que as convenções do gênero - padrões lexicais, sintáticos, retóricos e temáticos - dizem sobre aquela comunidade).

Uma terceira é pedir aos estudantes para entrevistar um informante em seu campo de atividade.

Uma última é fazer um projeto de campo que geraria: 1. observações e notas de campo sobre o ambiente e os participantes; 2. entrevistas com informantes, incluindo anedotas, citações, relatos e histórias orais; 3. artefatos materiais e escritos, tais como: textos, objetos que tenham significado cultural; 4. artefatos visuais, tais como: fotos dos lugares e dos participantes; 5. material de fonte prévia (ao menos duas fontes: uma escrita e outra de natureza diferente). 
Autores vinculados a esta tradição defendem que princípios etnográficos (observações de interações linguísticas de um grupo, participação em grupo, entrevistas com indivíduos que leem e escrevem um determinado gênero) podem situar a análise de gênero e dar aos estudantes acesso a contextos autênticos de uso da linguagem e, assim, criticamente engajá-los em práticas textuais e culturais.

Em função desse objetivo, eles oferecem um roteiro para a análise de gêneros, uma verdadeira etnografia da escrita.

1. coletar amostras de gênero - tentar coletar amostras de gênero de mais de um lugar através da observação de cenas de escrita, de forma a obter um quadro acurado da complexidade desse construto;

2. identificar a cena e descrever a situação na qual o gênero é usado. Para identificar uma cena mais ampla na qual o gênero é usado, busque respostas sobre a situação do gênero nas questões seguintes:

Ambiente: Onde o gênero aparece? Como e quando é transmitido e usado? Com que outros gêneros este gênero interage?

Assunto: A que tópicos, questões e ideias este gênero se endereça? Quando as pessoas usam este gênero? Sobre que tratam outros gêneros com os quais um determinado gênero interage?

Participantes: quem usa o gênero?

Escritores: quem escreve os textos nesse gênero? São possíveis múltiplos escreventes? Que papéis eles desempenham? Que características devem os escritores deste gênero possuir? Sob que circunstâncias os escritores deste gênero escrevem? (em time, no computador, na pressa);

Leitores: quem lê os textos neste gênero? Existe mais de um tipo de leitor para este gênero? Que papéis eles desempenham? Que características devem os leitores deste gênero possuir? Sob que circunstâncias os leitores leem este gênero? (por prazer, numa sala de espera, apressadamente).

Propósito: Por que os escritores escrevem este gênero e por que os leitores o leem? Que motivos levam as pessoas a usarem este gênero?

\section{3. identificar e descrever padrões nos aspectos do gênero}

Que aspectos recorrentes a amostra compartilha? Por exemplo:

Que conteúdo é tipicamente incluído? O que é excluído? Como o conteúdo é tratado? Que tipo de exemplos é usado? O que conta como evidência? (testemunha pessoal, fatos etc.). 
Que apelos retóricos são usados? Que apelos para o logos, pathos e ethos aparecem?

Como os textos são estruturados em gêneros? Quais são as suas partes e como são organizadas?

Em que formatos os textos são apresentados neste gênero? Que layout ou aparência é comum? Quão longos são estes textos? Eles são simples ou complexos? Utilizam sentenças variadas? Eles compartilham de certo estilo?

Que tipos de palavras são mais comuns? Utiliza-se de certos tipos de jargão? Gírias são usadas? Como você poderia descrever a voz do escritor?

4. analisar o que esses padrões revelam sobre a situação ou cena?

O que esses padrões retóricos revelam sobre o gênero, sua situação e a cena na qual é usada? Por que esses padrões são significativos? O que se pode aprender sobre as ações que são desempenhadas através do gênero, ao observar seus padrões de linguagem? A consideração dessas questões deve ter como foco:

Que saberes e crenças os participantes devem ter para entender ou apreciar o gênero?

Quem tem acesso ao gênero e quem é excluído?

Que papéis exercidos pelos escritores ou leitores encorajam ou desencorajam o gênero?

Que valores, crenças, objetivos e pressuposições são revelados através dos padrões do gênero?

Como o tema do gênero é tratado? Que conteúdo é considerado mais importante? Que conteúdos (tópicos, detalhes) são ignorados?

Que ações o gênero ajuda tornar possível? Que ações o gênero torna difícil?

Que atitude relativa aos leitores é embutida no gênero? Que atitude relativa ao mundo é embutida no gênero?

Trabalhos como os de Swales, denominados textografia, de Ann Johns, focados nos estudantes como pesquisadores, e de Devitt, Reiff e Bawarshi, conhecidos como etnografia da escrita, indicam como os métodos etnográficos, tais como: observação de lugares físicos em que se realizam atividades com gêneros e entrevistas com usuários de gêneros, podem fornecer acesso a determinadas comunidades discursivas e a seus usos de linguagem e, em decorrência, propiciar o domínio de gêneros.

\section{Considerações finais}


A discussão que desenvolvemos neste artigo destaca a natureza taxonômica que marca os estudos tradicionais de gênero textual e mapeia os avanços nesta área de estudos, destacando contribuições oferecidas por diferentes abordagens teóricas as quais reorientam a compreensão do fenômeno ao estabelecerem critérios de descrição e explicação que levam em conta a dinâmica da interação e as matrizes pragmáticas constituintes da variedade textual. O resgate desses movimentos epistemológicos, delineados como trilhas para a compreensão do assunto, busca contribuir para uma melhor compreensão do conceito de gênero e, consequentemente, das implicações que dela decorrem no processo de ensino-aprendizagem da língua.

Centramos nossa reflexão na dispersão/unificação que se observa relativamente à discussão desse construto, tanto no nível teórico quanto prático. Embora haja um consenso de que o gênero é uma entidade complexa, é exatamente essa complexidade que restringe tentativas de demarcação de fronteiras teórico-analíticas e que dificulta tomadas de posição quanto à abordagem dessa entidade como um objeto de ensino.

Ao longo do texto, apresentamos diferentes abordagens teóricas e os estudiosos a elas filiados, destacando seus interesses teórico-analíticos e os conceitos-chave por eles desenvolvidos. Nesse mapeamento, observou-se a dificuldade de se delinear um quadro ontológico capaz de demarcar aspectos definidores. A natureza flutuante e cruzada das descrições e explicações oferecidas pelos estudiosos aponta para a natureza multidimensional, processual e relacional do fenômeno, impossibilitando qualquer análise parcial da questão. No campo aplicado, a situação não é diferente. A dificuldade se dá em função de se ensinar os gêneros de modo explícito ou implícito. Duas tradições aqui se destacam: uma mais voltada para os aspectos textuais; outra direcionada para a situação retórica.

No fechamento da discussão, destaca-se a descrição de um método alternativo de análise de gêneros textuais - a perspectiva etnográfica, considerada como uma abordagem situada que cruza texto e fronteiras de contexto. Reconhecida como uma 'etnografia da escrita', esta análise de gêneros se mostra produtiva e eficaz para o acesso a contextos autênticos de uso da linguagem, engajando os alunos em determinadas práticas textuais e culturais.

Em síntese, defendemos que trabalhar gêneros no contexto escolar exige compreender esse conceito e ter como base as variadas perspectivas teóricas, podendo fazer uso destas na sala de aula de maneira consciente e crítica. 


\section{REFERÊNCIAS}

ARAÚJO, A. D. Lexical Signalling: a Study of Unspecific-Nouns in book Reviews. Tese de Doutorado UFSC, Florianópolis, 1996.

BAKHTIN, M. M. (1979). Estética da Criação Verbal. São Paulo: Martins Fontes, 1992, p. 261-306.

BATHIA, V. K. Analyzing Genre: Language Use in Profissional Settings. London: Longman, 1993.

BAWARSHI, A. Genre and the invention of the writer: Reconsidering the place of invention in composition. Logan, Utah: Utah State University Press, 2003.

BAWARSHI, A; REIFF, M. J. Gênero: teoria, pesquisa e ensino. Tradução de Benedito Gomes Bezerra. São Paulo: Parábola, 2013.

BAZERMA, C. Gênero, Agência e Escrita. Organização de Angela Paiva Dionísio e Judith Chambliss Hoffnagel. São Paulo: Cortez, 2006.

- Gêneros textuais, tipificação e interação. Organização de Angela Paiva Dionísio e Judith Chambliss Hoffnagel. São Paulo: Cortez, 2005.

BIASI-RORIGUES, B. Estrategias de condução de informação em resmos de dissertações. 1998. Tese-(Doutorado em Linguistica)- Centro de Comunicação e Expressão, Universidade Federal de Santa Catarina, Florianópolis, 19998

BRASIL. Ministério da Educação e do Desporto. Secretaria de Educação Fundamental. Parâmetros curriculares nacionais terceiro e quarto ciclos do ensino fundamental: introdução aos parâmetros curriculares nacionais. Brasília, DF: MEC/SEF, 1998.

BRONCKART, Jean-Paul. Atividade de linguagem, textos e discursos: por um interacionismo sócio-discursivo. São Paulo: EDUC, 1999.

BEZERRA, B. G. A propósito da "síntese brasileira" nos estudos de gêneros. Revista de Estudos da Linguagem, Belo Horizonte, v. 24, n. 2, p. 465-491, 2016.

BUNZEN, C. O ensino de "gêneros" em três tradições: implicações para o ensino aprendizagem de língua materna. In: COVRE et al. (Org.).Quimera e a peculiar atividade de formalizar a mistura do nosso café com o revigorante chá de Bakhtin. São Carlos: Grupos de Estudos dos Gêneros do Discurso, 2004, p. 221-257. 
COE, R. M. The new rhetoric of genre: writing political briefs. In: JOHNS, Ann. M. (Ed.). Genre in the classroom: multiple perspectives, 2002. p. 197-210.

CHRISTIE, F. Genre theory and ESL teaching: a systemic functional perspective. TESOL Quartely, v. 33, n. 4, p. 759-763, 1999.

DEVITT, A. J.; REIFF, M. J.; BAWARSHI, A. Scenes of writing: strategies for composing with genres. New York: Longman, 2004.

FAKHRUDDIN, W. F. W. W.; HASSAN, H. A Review of Genre Approaches within Linguistic Traditions. LSP International Journal, v. 2, Issue 2, January, p. 53-68, 2015. FLOWERDEW, J. Genre in classroom: A linguistic approach. In: JOHNS, A. M. (ed.). Genre in classroom: multiple perspectives. Mahwah,NJ: Lawrence Erlbaum, 2002, p. 43-72.

FREEDMAN, A; MEDWAY, P. Genre and the new rhetoric. London: Taylor \& Frances, 1994.

HALLIDAY, M. A. K. An introduction to Functional Grammar. London: Edward Arnold, 1985.

Part A. In: Halliday, M. A. K.; Hasan, R. (eds.). Language, Context, and Text: Aspects of Language in a Social-Semiotic Perspective. Oxford, OUP, 1989, p. 149.

HASAN, R. The structure of a Text. In: Halliday, M. A. K.; Hasan, R. (eds.). Language, Context, and Text: Aspects of Language in a Social-Semiotic Perspective. Oxford: Oxford University Press, 1985, p. 52-68.

Part B. In: Halliday, M. A. K.; Hasan, R. (eds.). Language, Context, and Text: Aspects of Language in a Social-Semiotic Perspective. Oxford: OUP, 1989, p. 52118.

HYLAND, K. Genre-based pedagogies: a social response to process. Journal of Second Language Writing, 12, p. 17-29, 2003.

HYLAND, K. Stance and engagement: a model of interaction in academic discourse. Discourse Studies, v. 7, p. 173-192, 2005.

HYON, S. Genre in three traditions: Implications for second language teaching. TESOL Quarterly, v. 30, n. 4, p. 693-722, 1996.

JOHNS, A. M. Genre and Pedagogical Purposes. Journal of second language writing.

[S. 1], v.4, n.2, p.181-190, 1995.

JOHNS, Ann M. Genre in the classroom: multiple perspectives. Mahwah, N. J.: Erlbaum, 2002. 
JOHNS, A M. ET AL. Crossing the boundaries of genre studies: commentaries by experts. Journal of Second Language Writing, n. 1, p.234-249, 2006.

KERN, R. Literacy and Language Teaching. Oxford: Oxford University Press, 2000.

MACHADO, A. R. "Para (re)pensar o ensino de gêneros: esclarecendo conceitos do interacionismo sócio-discursivo. In: MEURER, J. L.; BONINI, A.; MOTTA-ROTH, D. (Orgs.). Gêneros: teorias, métodos, debates. São Paulo: Parábola, 2005.

MARTIN, J. R. Close Reading: Functional Linguistics as a Tool for Critical Discourse Analysis. In: UNSWORTH, L. (Org.). Researching Language in Schools and Communities: Funcional Linguistics Perspectives. London: Cassell, 2000, p. 275-302.

MEURER, J. L.; BONINI, A.; MOTTA-ROTH, D. Gêneros: teorias, métodos, debates. São Paulo: Parábola, 2005.

MILLER, C. 'Genre as social action'. In: FREEDMAN, A; MEDWAY, P (orgs.). Genre and the New Rhetoric. London : Taylor \& Francis Publishers, 1994.

MOTTA-ROTH, D. Análise crítica de gêneros: contribuições para o ensino e a pesquisa de linguagem. D.E.L.T.A., v. 24, n. 2, p. 341-383, 2008.

OLIVEIRA, M. S. O Gênero Textual: teoria e prática. Texto apresentado no GELNE, Salvador/BA, no período de 4, 5 e 6 de setembro de 2000. Gêneros textuais e letramento. Revista Brasileira de Linguística Aplicada. Belo Horizonte, v. 10, n. 2, p. 325-345, 2010.ROTHERY, J. Making changes: developing an educational linguistics. In: HASAN, Ruqayia; WILLIAMS, Geoff (Ed.) Literacy in Society. London: Longman, 1996, p. 86-123.

]SILVEIRA, M. I. M. Análise de Gênero textual: concepção sócio-retórica. Maceió: EDUFAL, 2005.

SWALES, J. M. Genre analysis: English in academic and research settings. Cambridge:Cambridge University Press, 1990.

Other floors, other voices: a textography of a small university building. Mahwah, NJ: Lawrence Erlbaum, 1998.

VIAN JR, O. Beyond the Three Traditions in Genre Studies: a Brazilian Perspective. Paper presented at Genre 2012- Rethinking Genre 20 Years Later. An International Conference on Genre Studies. Carleton University, Ottawa. 2012. 